\title{
Thirty years of EJCN: a time for reflection
}

\author{
MJ Soares $\mathbb{D}^{1} \cdot$ MJ Müller ${ }^{2}$
}

Received: 27 April 2018 / Accepted: 27 April 2018

(c) Macmillan Publishers Limited, part of Springer Nature 2018

This year marks the $30^{\text {th }}$ anniversary of EJCN's contribution to nutrition science. In reality, we have been around for a fair while longer [1, 2]. Many things have changed over these 30 years: from typewritten manuscripts and postal submissions to computer-based programs that auto correct, stylize documents, and insert references from a virtual library, to aid an immediate online submission on the journal's website. It should come as no surprise that these days some of our top nutrition scientists publish more than 50 papers a year! As a traditional, non-society journal, we have always been intimately concerned with issues on human and clinical nutrition from around the globe. We offer the readership a range of study design from the epidemiology of diet and disease, to randomized trials that test the efficacy of nutrients or dietary patterns in at-risk groups or patients with acute illness. Our current publications reflect this continued effort at internationalization [2]. About $56 \%$ of our papers are now from outside Europe, with the USA and Canada now contributing about $17 \%$, South East Asia 17\%, and rest of the world 22\%. Over this period there has been a steady improvement in our impact factor which currently hovers around the value of 3 [3].

We owe much of our success to the vision of our forebears, and were extremely happy to honor their memories with the establishment of two research awards last year [4]. The contributions of our past editorial boards together with the unflagging support of our publishers over these years, needs to be acknowledged as well. Needless to say, we would not exist without the continued support of the scientists who have entrusted their research outcomes to EJCN. We live in challenging times, and the push and pull on the discipline of

\section{MJ Soares}

m.soares@curtin.edu.au

1 School of Public Health, Curtin University, Perth, Western Australia, Australia

2 Institute of Human Nutrition and Food Sciences, Christian Albrechts Universität, Kiel, Germany nutrition is of great concern [5]. A special thank you has to go out to our editorial board and reviewers who make the time from their academic duties, and offer us their tireless service and expertize in upholding our standards. So how do we grow our journal in this frenzied and competitive space? We touch upon two aspects of our future plans that we feel are important in this regard.

\section{Quality manuscripts}

We live in an age where academic publishing is essential to the "survival" of the scientist, as this is intimately linked to their chances of research grant success and academic promotion. The dramatic escalation in the number of nutrition and health related journals in the last decade exploits this weakness of our system, with many new journals of questionable legitimacy and scientific standards, promising astonishingly rapid publication times for a sizeable fee! Not surprisingly, shoddy submissions with inaccurate authorship assignments are on the rise, and we have to be ever vigilant of manuscripts that breach research integrity $[6,7]$. Then there are a host of other manuscripts that pass these tests, are seemingly perfect in composition, but in reality serve little purpose since they do not contribute to our further learning. Now, more than ever, we need to subscribe to tangible solutions for our global problems; malnutrition on the one hand and obesity-related chronic diseases, on the other. Our view is that nutrition will be best served by research designs that contribute to translatable outcomes. Cross sectional designs, especially those based on archived data and that reiterate old messages, are not helpful. We have hence made a decision not to progress such submissions to review. Population-based sampling addressing a novel hypothesis are a way forward, if they align with a future causative design. Similarly, short duration RCTs in a well-selected patient/participant groups do not allow translatable outcomes. We need long term effectiveness trials with requisite follow up to better appreciate the effects of dietary patterns/lifestyle changes designed for the 
Table 1 Greatest challenges to nutrition research for the next 30 years, as voted by the participants in a symposium in at Wageningen University in 2006

\begin{tabular}{ll}
\hline Rank & Challenge \\
\hline 1 & $\begin{array}{l}\text { Controlling obesity and insulin resistance through activity and } \\
\text { diet }\end{array}$ \\
2 & $\begin{array}{l}\text { Can diet delay cognitive decline? } \\
3\end{array}$ \\
$\begin{array}{l}\text { Restore the balance between private and public control of } \\
\text { nutrition research }\end{array}$ \\
4 & The reductionistic versus the food pattern approach \\
5 & Implementing diet in clinical practice \\
6 & How can we prove that lifestyle interventions work \\
7 & Diet and low-grade systemic inflammation \\
8 & From genetics to epigenetics \\
9 & Evidence-based segmented dietary guidelines \\
10 & How can we measure energy balance in free living people \\
11 & The use of substances from plants to prevent disease \\
12 & The role of $\alpha$-linolenic acid in coronary heart disease \\
13 & Reduction of salt in foods \\
14 & B-vitamins, homocysteine and cardiovascular disease
\end{tabular}

Reproduced with permission from Katan et al (2009)

management or alleviation of chronic diseases. Prospective cohort studies in contemporary population groups would serve a similar useful purpose, since nutrition policy/ recommendations should not have to rely on RCTs as their sole evidence base [8]. For a while now, there has been a call for data sharing across the sector; from funding agency to industry and academia. Provision of raw data, as precious as it is, allows future investigators the opportunity to reanalyze and test newer hypotheses towards clinical medicine outcomes [9], as well as cementing diet and disease relationships [10]. The EJCN, and other like-minded journals, support this move by requesting authors to make their data available on a publically accessible website, or have in place an approach for researchers to request such information.

\section{Nutrition agenda}

It has been argued that the diminishing input of research dollars from national and international health agencies has allowed the corporate world to drive the nutrition science being reported [5]. Strategizing to influence nutrition research outcomes for their gain is not new to the food industry [11]. A healthy journal acts as the gatekeeper for good science. While we decide what is of importance to our discipline, we should engage in focussed discussion in setting a nutrition agenda for the future. With this in mind, we have initiated a series of special issues; one on type 2 diabetes in Asia [12], another on recent advances in energy metabolism [13], with others in the pipeline. A decade ago, a group of scientists pondered the challenges that we would face in the next 30 years [14]. Those topics make for very interesting reading as they reflect current research activities and remind us how far we have to go. So is it time to revisit these or are there other research priorities? (Table 1). We are keen to hear from interested scientists and would be very happy to assist in driving such an endeavor.

We are very pleased to welcome you to this $30^{\text {th }}$ Anniversary edition and hope you enjoy its content. This celebratory issue offers a collection of papers by our editorial board members and special views of invited scientists. Clearly, the topics align with each author's research interests. However, we have deliberately challenged the traditional EJCN format, by asking each contributor to address, 'what is known on the topic', 'what is currently being done' and 'what do they wish to see happening' in their sphere of activity. Hopefully, such a commonality of format will help us achieve a greater readability of the subject, and the opportunity to ponder the questions therein. We sincerely thank all the authors of this issue for their contribution, and our colleagues from other journals for their good wishes. Furthermore, we are indebted to the readership for their support over the last 30 years, and look forward to a continued and stimulating association over the next thirty years.

\section{Compliance with ethical standards}

Conflict of interest The authors declare that they have no conflict of interest.

\section{References}

1. Shetty PS. A progress report and a tribute to our founding editor. Eur J Clin Nutr. 2011;65:1-2.

2. Müller MJ. EJCN: 25 years of progress. Eur J Clin Nutr. 2013;67:423.

3. Scimago journal and country rank. http://www.scimagojr.com/ journalrank.php?category=2916. Accessed 17th April, 2018.

4. EJCN Announcements. https://www.nature.com/ejcn/about/a nnouncements. Accessed 15th April, 2018.

5. Penders B, Wolters A, Feskens EF, Brouns F, Huber M, Maeckelberghe ELM, et al. Capable and credible? Challenging nutrition science. Eur J Nutr. 2017;56:2009-12.

6. Müller MJ, Landsberg B, Ried J. Fraud in science: a plea for a new culture in research. Eur J Clin Nutr. 2014;68:411-5.

7. Müller MJ, Soares MJ. The ethics of research publication. Eur J Clin Nutr. 2017;71:569.

8. Mann J. Discrepancies in nutritional recommendations: the need for evidence based nutrition. Asia Pac J Clin Nutr. 2002;11: S510-S515.

9. Naci H, Jacob Cooper J, Mossialos E. Timely publication and sharing of trial data: opportunities and challenges for comparative effectiveness research in cardiovascular disease Eur Heart J 2015; 1: $58-65$ 
10. Pinart, et al. Joint data analysis in nutritional epidemiology: identification of observational studies and minimal requirements. $\mathbf{J}$ Nutr. 2018;148:285-97.

11. Nestle M. Coca-Cola says its drinks don't cause obesity. Science says otherwise. The Guardian. https://www.theguardian.com/ commentisfree/2015/aug/11/coca-cola-obesity-health-studies

12. Soares MJ, Müller MJ. Type 2 diabetes in Asia: where do we go from here? Eur J Clin Nutr. 2017;71:801-2.
13. RACMEN Special Issue. Recent Advances and Controversies in Measurement of Energy Metabolism (RACMEM) Conference. Eur J Clin Nutr 2018 (In Press).

14. Katan MB, Boekschoten MV, Connor WE, Mensink RP, Seidell J, Vessby B, Willett W. Which are the greatest recent discoveries and the greatest future challenges in nutrition? Eur J Clin Nutr. 2009;63:2-10. 